$\xi_{p}=-1$

\title{
Prototype File Transfer Protocol Application for LAN and Wi-Fi Communication
}

\author{
Robbi Rahim ${ }^{1 *}$, Solly Aryza ${ }^{2}$, Pristisal Wibowo ${ }^{2}$, Adek Khadijatul Z Harahap ${ }^{3}$, Abdul Rahman Suleman ${ }^{3}$, Edi \\ Epron Sihombing ${ }^{3}$, Yuswin Harputra ${ }^{3}$, Muhammad Rahman Rambe ${ }^{3}$, Andysah Putera Utama Siahaan ${ }^{2}$, H Her- \\ mansyah $^{2}$, Ari Riswanto ${ }^{4}$, M Adhi Prasnowo ${ }^{5}$, Hardianto Djanggih ${ }^{6}$, Kisman Karinda ${ }^{6}, N_{\text {Nasrudin }}{ }^{7}$, Ika Agustina ${ }^{7}$ \\ ${ }^{1}$ Sekolah Tinggi Ilmu Manajemen Sukma, Medan, Indonesia \\ ${ }^{2}$ Universitas Pembangunan Pancabudi, Medan, Indonesia \\ ${ }^{3}$ Universitas Graha Nusantara Padangsidimpuan, Padangsidimpuan, Indonesia \\ ${ }^{4}$ Economic Education and Management, STKIP PGRI Sukabumi, Indonesia \\ ${ }^{5}$ Department of Industrial Engineering, Universitas Maarif Hasyim Latif, Sidoarjo, Indonesia \\ ${ }^{6}$ Universitas Tompotika Luwuk Banggai, Banggai, Indonesia \\ ${ }^{7}$ Politeknik Negeri Media Kreatif, Medan, Indonesia \\ *Corresponding authorE-mail: usurobbi85@zoho.com
}

\begin{abstract}
FTP (File Transfer Protocol) is one of the earliest Internet protocols developed. An FTP server can be accessed by using a URI (Universal Resource Identifier), using FTP file exchange between client and server is easier to do because the communication is done directly without going through an intermediary, for communication using FTP need to be designed an application that allows communication between the client and server directly without using the browser, for it is designed an FTP application using programming language in this case is Borland Delphi programming language, the ease of sending files between computers based on IP is a value added from the FTP application that is designed because most existing FTP applications can only send files between the server and the client in the internet network means that online must not be local area network or wide area network.
\end{abstract}

\section{Introduction}

At the present time, technological developments are very helpful to man in carrying out all its activities[1]-[5], especially in the field of data transmission[6]-[8]. The easier and faster the process of sending data from one host to another on a different network called routing has provided users with much easier time and efficiency[9], [10].

In the process of data communication between computers via the internet required a protocol[11], [12], which is a collection of rules that process communication between electronic devices, one of which is FTP (File Transfer Protocol)[13], [14]. FTP is one of the earliest Internet protocols developed, and is still used today to exchange files between FTP clients and FTP servers. An FTP server can be accessed by using a URI (Universal Resource Identifier), the FTP Client can perform data communications using URI. FTP servers can be accessed with Web Browser applications such as: Internet Explorer/Microsoft Edge, Mozilla Firefox, Opera, Safari, Google Chrome, and other Web Browser applications[6]. However, the use of the Web Browser application to access the FTP server can only display the linked list of files contained in an FTP server. This means that the Web Browser application can only be used to display the file list and download from the FTP server, while to perform the upload activity cannot use Web Browser application, but must use the FTP Client application. FTP
Client Applications can be used to exchange files both download and upload.

This research creates an FTP client application that will be designed to perform file transactions between FTP clients and FTP servers in a local area network so that it does not require internet connection, file transfer is only limited to copying files from server to client.

\section{Methodology}

TCP/IP (Transmission Control Protocol / Internet Protocol) is a group of protocols that allows a collection of computers to communicate and exchange data within a network in general, and the Internet in particular[15].

A protocol is a set of rules that allows a computer to connect with one another, usually in the form of time, sequence, error checking during data transmission[16]. Computers connected to the internet communicate with this protocol. Because using the same language, i.e. TCP/IP protocol, different types of computers and operating systems are not a problem. So if a computer uses the TCP/IP protocol and connects to the internet, then the computer can connect directly to other computers in any world that is also connected to the internet[17], [18].

Wi-Fi is simply a cable replacement so your computer can access the Network / LAN network[14], [19]. So if you have to look for cables and plugs to connect with LAN, then with this Wi-Fi you 
do not have to bother looking for cable, but just look for signal only. When the signal is found (and you are allowed in), then you will be connected to the LAN. The required settings are the same as regular LAN connections. From the LAN side there should be a DHCP server (which provides IP settings, DNS, Default Gateway automatically), so the computer simply uses the existing 'default' (i.e. Automatic Configuration). Later computer will read signal from AP, automatically configuration of Wi-Fi card in computer will be adjusted[14], [18], [20], [21].

File Transfer Protocol (FTP) is a protocol that serves to exchange files in a network that supports TCP/IP protocol. Two important things that exist in FTP are FTP server and FTP Client. FTP server running software used to exchange file, which always ready to give FTP service if get request from FTP client. An FTP client is a computer that requests a connection to an FTP server for the purpose of exchanging files (uploading or downloading files). Here is a file delivery architecture using FTP.

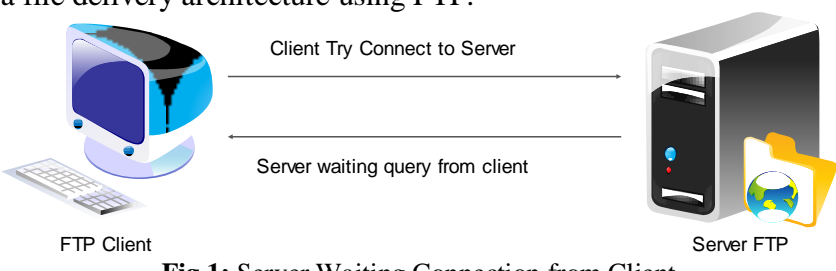

Fig 1: Server Waiting Connection from Client

Figure 1 shows the status of server and client which will be connected to each other to upload files from client to server, connection process between server and client can only be done after server open a port and IP Server number which can be used by client to connect, without port and IP number which is true then the client cannot connect, image 2 client open the connection to the server so that server and client connect.
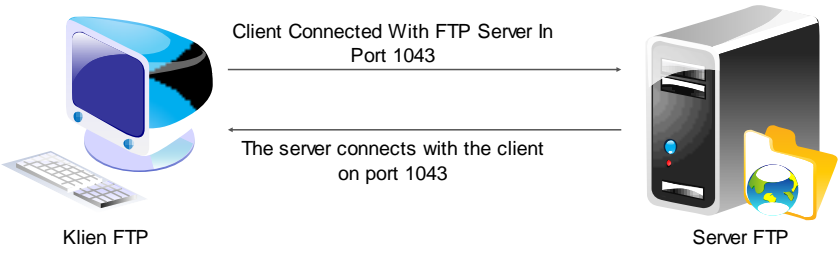

Fig 2: Client Opens the Connection to an FTP Server

\section{Results and Discussion}

A system in order to run as desired because the computerized system cannot be separated between Hardware and Software. Software that clearly supports Hardware or software such as Operating System and Borland Delphi 7 with Borland Socket feature.

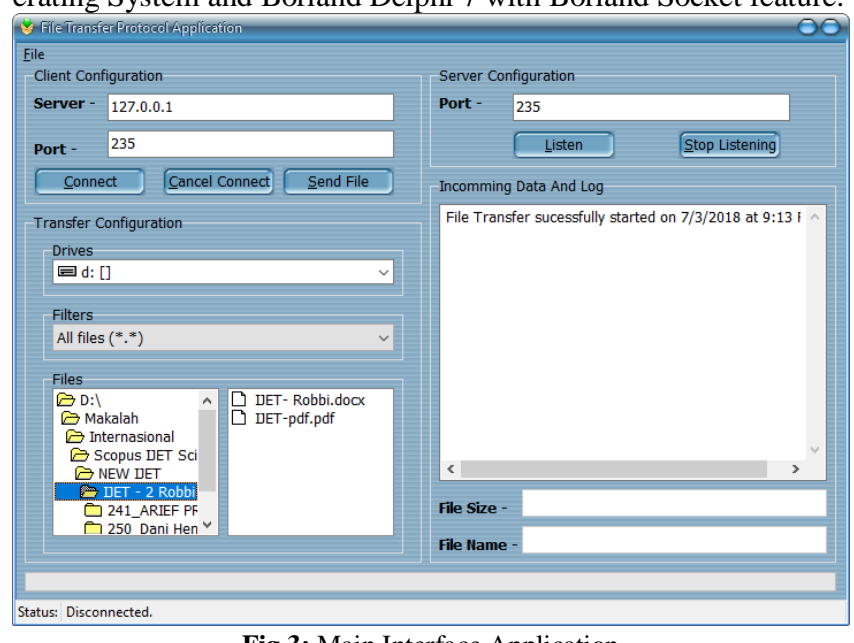

Fig 3: Main Interface Application

The process of file transfer as an experiment is done on a localhost network as simulation; Figure 3 shows the condition of network with disconnected status because server hasn't open port for client to connecting, the following picture shows the server connection in listening mode to wait for connection from the client.

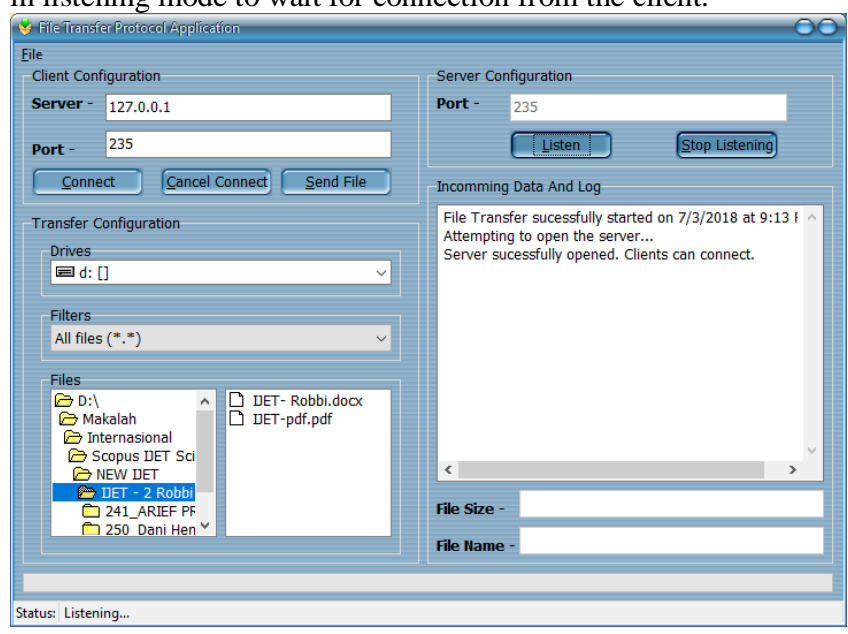

Fig 4: Server on Listening Mode

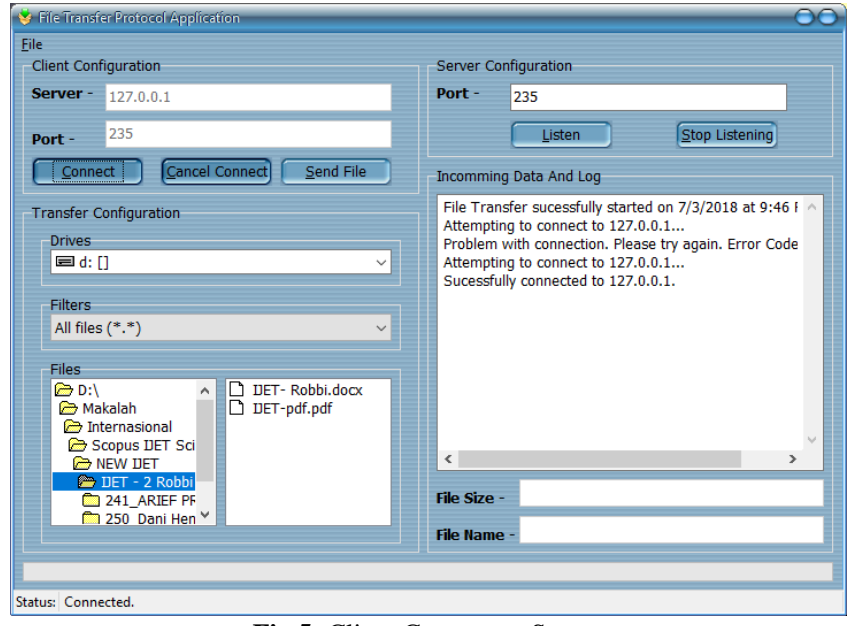

Fig 5: Client Connect to Server

Figures 4 and 5 show the condition of connection client and server, the connection allows to transmit the file between server and client and also vice versa. Figure 6 is the process of sending file between computers.

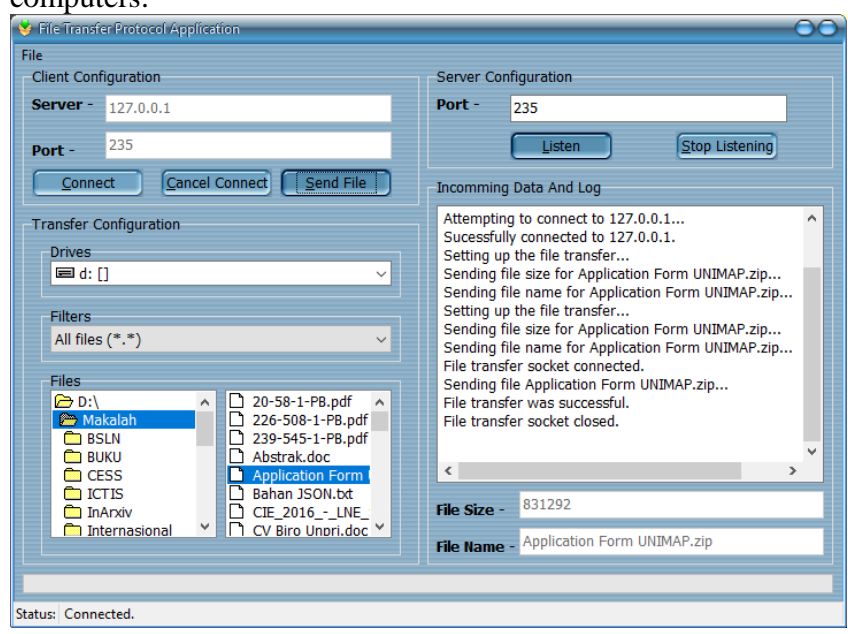

Fig 6: Sending File

Figure 6 shows the process of sending the file in batch without any problems and the connection between server and client running properly. Testing the submission of the file is obtained that the process of delivery depends on the file type and size of the file, files recognized by the operating system will be faster sent even though the file is very large more than $10 \mathrm{MB}$ in the case of files that are not common with the same size will be longer delivered. 


\section{Conclusion}

Based on the above information it is concluded that the application file transfer protocol designed using Borland Delphi can run well with the transfer process above $30 \mathrm{MB}$, the use of Borland socket in the application can handle many errors that occur on the network so as to minimize the damage of the files sent. The development of this application is possible by adding a feature of compression and encryption on files sent on the network so as to make the files more secure when sent.

\section{References}

[1] [1] D. Abdullah et al., "Super-Encryption Cryptography with IDEA and WAKE Algorithm," J. Phys. Conf. Ser., vol. 1019, no. 1, p. 012039, Jun. 2018.

[2] [2] G. Gunawan et al., "Mobile Application Detection of Road Damage using Canny Algorithm," J. Phys. Conf. Ser., vol. 1019, no. 1, p. 012035, Jun. 2018.

[3] [3] M. Mesran, M. Syahrizal, and R. Rahim, "Enhanced Security for Data Transaction with Public Key Schnorr Authentication and Digital Signature Protocol," ARPN J. Eng. Appl. Sci., vol. 13, no. 11, pp. 3839-3846, 2018.

[4] [4] R. Rahim, "Man-in-the-middle-attack prevention using interlock protocol method,” ARPN J. Eng. Appl. Sci., vol. 12, no. 22, pp. 6483-6487, 2017.

[5] [5] J. Simarmata et al., "Prototype Application Multimedia Learning for Teaching Basic English," Int. J. Eng. Technol., vol. 7, no. 2.12, pp. 264-266, Apr. 2018.

[6] [6] N. Kurniasih et al., "Prototype Application Hate Speech Detection Website Using String Matching and Searching Algorithm," Int. J. Eng. Technol., vol. 7, no. 2.5, pp. 62-64, Mar. 2018.

[7] [7] R. Rahim et al., "Searching Process with Raita Algorithm and its Application," J. Phys. Conf. Ser., vol. 1007, no. 1, p. 012004 , Apr. 2018.

[8] [8] T. Listyorini and R. Rahim, "A prototype fire detection implemented using the Internet of Things and fuzzy logic," World Trans. Eng. Technol. Educ., vol. 16, no. 1, pp. 42-46, 2018.

[9] [9] A. Ikhwan, D. Nababan, and R. Rahim, "Selective-Reject ARQ for Identification Error in Frame Data," Int. J. Recent Trends Eng. Res., vol. 3, no. 1, pp. 89-94, 2017.

[10] [10]B. Maulana and R. Rahim, "GO-BACK-N ARQ APPROACH FOR IDENTIFICATION AND REPAIRING FRAME IN TRANSMISSION DATA,” Int. J. Res. Sci. Eng., vol. 2, no. 6, pp. 208-212, 2016.

[11] [11]S. M. P. Marichamy, S. Chakrabarti, "Overview of Handoff Schemes in Cellular Mobile Networks and Their Comparative Performance Evaluation,” IEEE Veh. Technol., pp. 1486-1490, 1999.

[12] [12]S. Network and M. Protocol, "Simple Network Management Protocol," RFC 1157, vol. 3, no. 1098, pp. 69-150, 2006.

[13] [13]J. Postel and J. Reynolds, "RFC 959 - File Transfer Protocol," Rfc 959, 1985.

[14] [14] a. Klemm, C. Lindemann, and O. P. Waldhorst, "A specialpurpose peer-to-peer file sharing system for mobile ad hoc networks," 2003 IEEE 58th Veh. Technol. Conf. VTC 2003-Fall (IEEE Cat. No.03CH37484), 2003.

[15] [15]R. Rahim et al., "Internet based remote desktop using INDY and socket component," Int. J. Eng. Technol., vol. 7, no. 2.9, pp. 44-47, 2018.

[16] [16]H. Nurdiyanto, R. Rahim, A. S. Ahmar, M. Syahril, M. Dahria, and H. Ahmad, "Secure a Transaction Activity with Base64 Algorithm and Word Auto Key Encryption Algorithm," J. Phys. Conf. Ser., vol. 1028, no. 1, p. 012053, Jun. 2018.

[17] [17]R. Yadav, "Client / Server Programming with TCP/IP Sockets," Client / Serv. Program. with TCP/IP Sockets, p. 24, 2007.

[18] [18]K. R. Fall and R. W. Stevens, "TCP: The Transmission Control Protocol (Preliminaries)," in TCP/IP Illustrated, Volume 1: The Protocols, 2011.

[19] [19]Dhanamma et al., "Classification of TCP Variants inside Wireless Networks," Classif. TCP Var. Insid. Wirel. Networks, vol. 4, no. 4, pp. 340-347, 2014.

[20] [20]V. C. M. L. Qixiang Pang, S.C. Liew, "Performance improvement of 802.11 wireless network with TCP ACK agent and autozoom backoff algorithm," in IEEE Vehicular Technology Conference, 2005.

[21] [21]M. Alizadeh et al., "Data center TCP (DCTCP)," ACM SIGCOMM Comput. Commun. Rev., vol. 40, no. 4, p. 63, 2010. 